\title{
The Problems and Strategies of Innovative Transformation of the Manufacturing Industry
}

\author{
Boev A.G.* \\ AI VR «Analytical center of the \\ Voronezh region government» \\ Voronezh, Russia \\ e-mail: a_boev@list.ru
}

\author{
Kolodyazhnaya A.A. \\ Saint-Petersburg State University \\ Saint-Petersburg, Russia \\ e-mail: nastya-kolodyazhnaya @mail.ru \\ Lutsenko M.S. \\ Voronezh State Technical University \\ Voronezh, Russia
}

\author{
Anisimov Y.P. \\ Voronezh State Technical University \\ Voronezh, Russia
}

\author{
Lubyanskaya E.B. \\ Voronezh State Technical University \\ Voronezh, Russia \\ Shendrikova O.O. \\ Voronezh State Technical University \\ Voronezh, Russia
}

\begin{abstract}
This study identifies the topical issues of innovative transformation of the manufacturing industry in the Russian Federation. A structural and statistical analysis of the basic indicators of innovative development and the state of the technological base of Russian manufacturing industry is observed. Positive and negative trends of these processes are noted; the list of system problems of processing enterprises is revealed - such as low level of productivity, insufficient level of innovative activity, progressive depreciation of fixed assets, reduction of internal expenses for $R \& D$, as well as unstable dynamics of the high-tech sector of machine-building industry. It was found that the most significant factor, preventing the transition of the domestic manufacturing industry towards the innovative development, is not the factor of infrastructure restrictions, but a number of institutional and environmental contradictions. The authors stand for the position that the elimination of these contradictions is possible due to the development of innovation ecosystem that can effectively create the necessary business environment and eradicate existing barriers to business cooperation for industrial, scientific, educational and other organizations. The objects of this ecosystem will be characterized by a state of stable innovation and investment, a state of high professional credibility, an established network of communications, a free transfer of knowledge and technologies, as well as high-tech methods of production and experimental engineering, which contribute to the development of the production culture of employees and the spirit of innovative entrepreneurship. A set of measures for the creation and development of an innovation ecosystem is proposed, which implies a balanced transformation of the internal and external environment of the Russian processing industry. The set includes: 1) the reformation of engineering and processing enterprises, aimed to: adjust the existing strategies and to improve the quality and flexibility of management methods; update the content of management functions; transform and computerize the business processes; optimize the organizational, economic, and structural model of an industrial enterprises; 2) the territory development for innovative pilot projects in Russia in order to accelerate the implementation and commercialization of product innovations; 3 ) the development of
\end{abstract}

a system of priority state support for those firms that produce the product innovations; 4) measures for improving the quality of national industrial projects for targeted use; 5) optimization of the business climate by introducing the cluster production for further integration of research and engineering companies in business environment; 6) training of qualified staff for the purposes of innovation development in a highly technological economy.

Keywords - innovation development, transformation of enterprises, innovation ecosystem, institutional changes, processing industry.

\section{INTRODUCTION}

One of the most important economic challenges in Russia is the task of increasing the competitiveness of the manufacturing industry and transfer of domestic manufacturing enterprises to an innovative path of development.

The manufacturing industry is a set of manufacturing enterprises, organizations and other structures whose business models are based on the physical transformation of raw materials into finished products (or their equivalents), and technological processes are characterized by multiple stages and processing. The core of the manufacturing industry consists of machine-building, metallurgical, chemical, woodworking, glass and other industries.

The processing complex is of particular strategic importance for the Russian Federation. Its activities are related to the production of goods and services with high added value and largely determine the level and prospects of socioeconomic, scientific and technological development of the country. In 2019, the share of manufacturing companies to gross domestic product was $12.7 \%$ (the upward trend).

In the current market conditions, the most important competitive advantage is the ability of enterprises to master 
new technologies and methods of work, introduce innovations and create high-tech products. In addition, the innovative activity and susceptibility of the manufacturing sector to modern technological solutions is a necessary condition and an effective catalyst for the formation and scaling of the national digital economy. In this regard, ensuring the innovative nature of management and production at industrial enterprises becomes a dominant role for the processes of modernization of Russian industry.

Currently, the peculiarity of the development of the world economy is that modern inventions and innovations are increasingly "subversive" (revolutionary) statement, that is, they do not only develop a product or technology, but completely destroy traditional markets and create fundamentally new niches. Moreover, this process can occur unpredictably and in a very short time. Under these conditions, no production company is guaranteed leadership or technological lead in the world market, which obliges their managers and specialists to constantly develop and implement innovations, act proactively and systematically improve management and production models.

The risks of rapid "zeroing" of the results achieved due to the emergence of innovations and radically new digital tools, a significant reduction in the life cycles of technologies and a high rate of obsolescence of competencies determine the relevance of finding effective directions for the dynamic innovative transformation of the Russian manufacturing sector and solving strategic problems in this industry.

\section{METHODOLOGY AND ANALYSIS}

The purpose of the article is to study the main problems of transformation and innovative development of the Russian manufacturing industry, as well as to determine the strategic areas for their resolution.

The object of the study is industrial enterprises and organizations forming the country's processing complex. The subject of the analysis is economic relations and problems determining the state of innovation activity and the results of innovative development of processing companies in the Russian Federation.

The hypothesis of the study is that an important limitation on the path of innovative development of the manufacturing industry is a set of systemic problems, the solution of which must be carried out on the basis of balanced management, cultural and institutional, functional, processing, structural and other changes in the internal and external enterprise environment.

The methodological basis of the research is the work of authoritative Russian and foreign scientists in the field of innovative development - Yu.P. Anisimov [1], I.P. Bogomolova, Yu.V. Zhuravlev [2], S.V. Valdaytsev [3], G.B. Kleiner [4], L.R. Graham, Ch. Edquist.

A quantitative structural and statistical analysis of the parameters of the innovative-technological and economic state and functioning of the Russian manufacturing industry is used as a reference method of the study.
At present, the quantitative parameters of the development of the manufacturing sector in Russia were perceived as quite contradictory. Thus, in 2013-2018, the volume of shipments in the manufacturing sector increased by 1.6 times and reached 43 trillion rubles. The index of industrial production has remained stable at $102.5 \%$ in recent years, which indicates a moderate growth in the manufacturing industry. At the same time, in 2016-2018, the number of newly created manufacturing industries in Russia (1,242 units) decreased by $25 \%$ compared to 2013-2015 (1,656 units). There have been crisis trends in the high-tech manufacturing segment, which is the most vulnerable to sanctions restrictions. For 2014-2018, the production index in it fell by 22.3 p.p. and amounted to $95.1 \%$ (fig. 1).

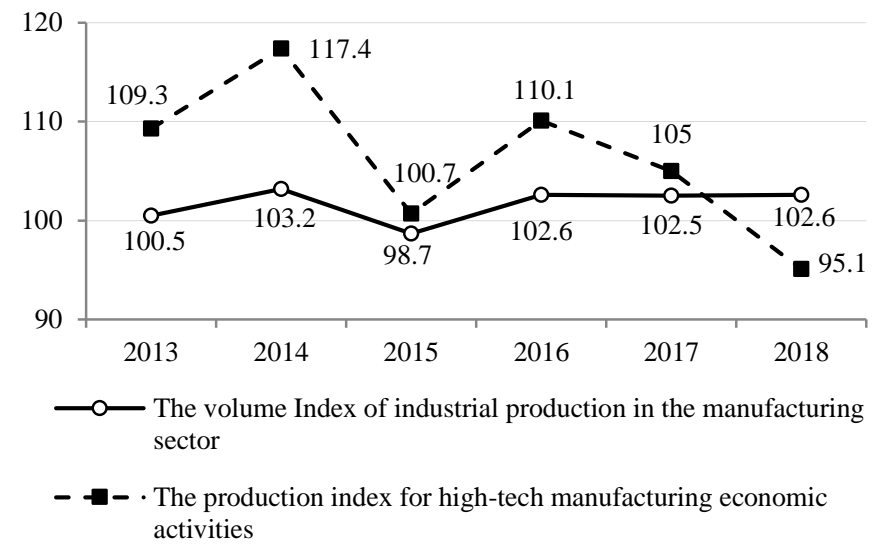

Fig. 1. Dynamics of the manufacturing indices in the Russian manufacturing sector [5]

The simultaneous development of pronounced positive and negative changes, as well as sharp swings in economic perfomance, indicate a certain instability in the functioning of the manufacturing industry in Russia and its high sensitivity to external destabilizing factors (international trade restrictions, inflation, currency fluctuations, tax reforms, etc.).

It should be noted that the inconsistency of economic results and the strong dependence of processing enterprises on market conditions are the result of accumulated systemic problems. To date, one of the main obstacles to the formation of a competitive industrial complex in Russia is outdated and inefficient management and production and technological models of the majority of industrial organizations. The following problematic aspects and risks of development of the domestic manufacturing sector are evidence of the crisis of these models:

1) a persistently low level of productivity. Currently, Russia lags behind the United States and European countries against this indicator, especially in high-tech areas, 3-5 times [6]. Improving the competitiveness of industrial production and ensuring multiple growth rates of labor efficiency is one of the most important tasks set by the Russian Government for the development of the national economy. During 2013-2018, 225 thousand high-performance jobs were created in the manufacturing sector, but they enhance the productivity in their segment by only $8.7 \%$ over 5 years (fig. 2 ). 


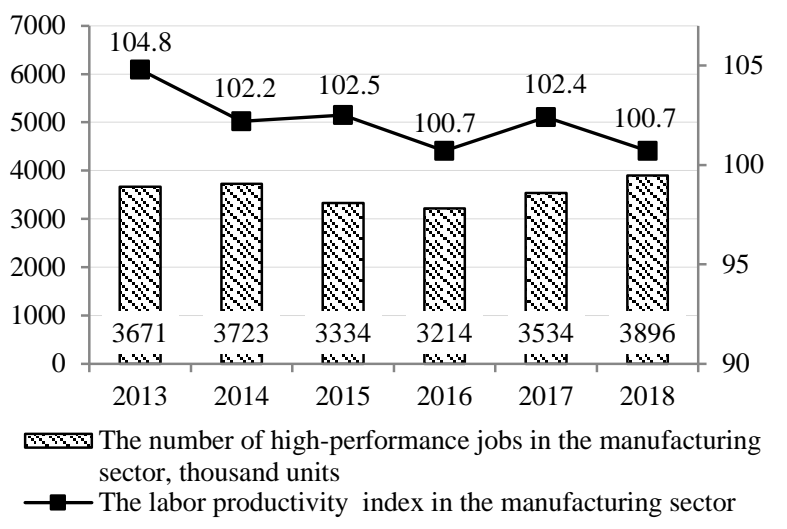

Fig. 2. Labor productivity in the Russian manufacturing sector [5]

On the one hand, this imbalance is largely due to the sanctions factor, which led to a drastic reduction of more than 500 thousand effective jobs in 2014-2016, which were restored only by 2018-2019. On the other hand, a relatively low correlation between highly productive jobs and real productivity growth has been observed in the manufacturing sector for quite a long time (more than 10 years), which indicates the presence of institutional, managerial and other unresolved aspects that limit the effectiveness of the implementation the innovative and productive potential of the Russian industrial enterprises and complexes.

2) high and progressive depreciation of fixed assets of industrial enterprises preventing the processes of reindustrialization, innovatization and digitalization of the domestic economy. The analysis of the situation shows that over the past 10 years, there has been no radical and largescale modernization of the production sector in Russia. In most cases, the re-equipment of companies was local in nature. Moreover, the situation deteriorated in some strategically important areas. Thus, in 2008-2017, the degree of depreciation of fixed assets in the manufacturing segment of the industry increased from 45.6 to $49-50 \%$;

3) insufficient innovation level of enterprise engagement creating risks of reducing the competitiveness and scientific and technological potential of the domestic industry. It should be noted that in an emerging a high-tech digital economy, the systematic introduction of innovations is one of the key factors for the effective transformation and development of the industrial complex. Production statistics show that in 2010-2018, the share of manufacturing sector organizations implementing technological innovations remained consistently low and was at the level of $11-12 \%$ (the upward "spike" in technological innovation activity on the chart in 2017-2018 is due solely to the adjustment of the Rosstat methodology in accordance with new international standards) (fig. 3). A similar issue is observed with regard to the use of organizational and marketing innovations. The share of Russian processing companies that implement them is only $\sim 3 \%$.

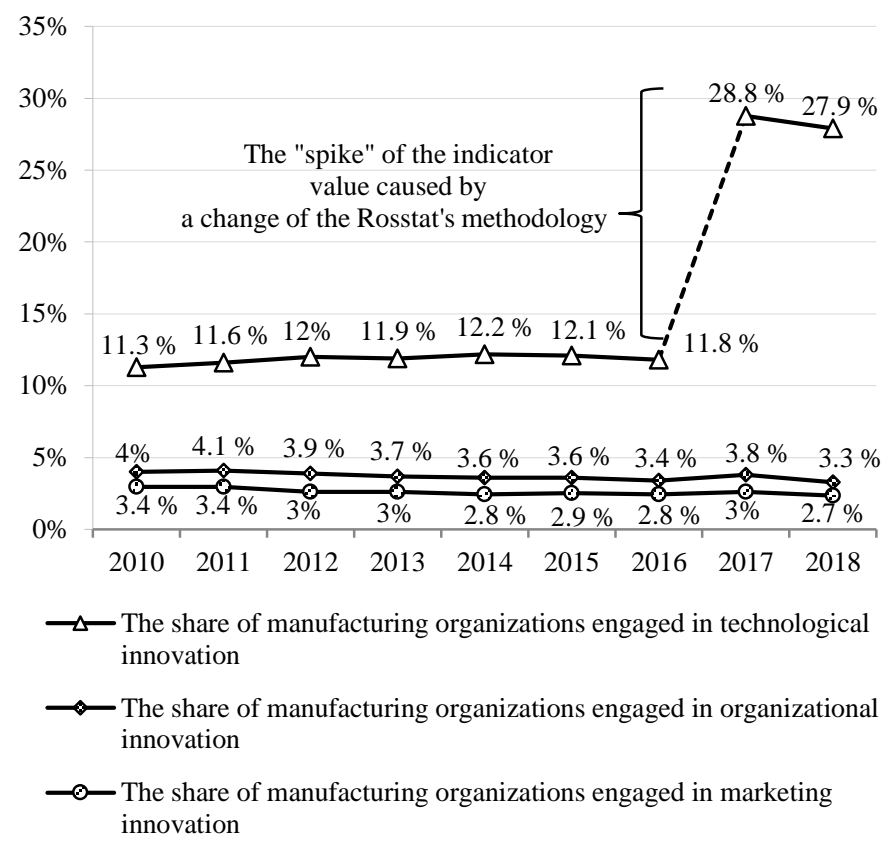

Fig. 3. The shares of manufacturing sector organizations implementing innovation [5]

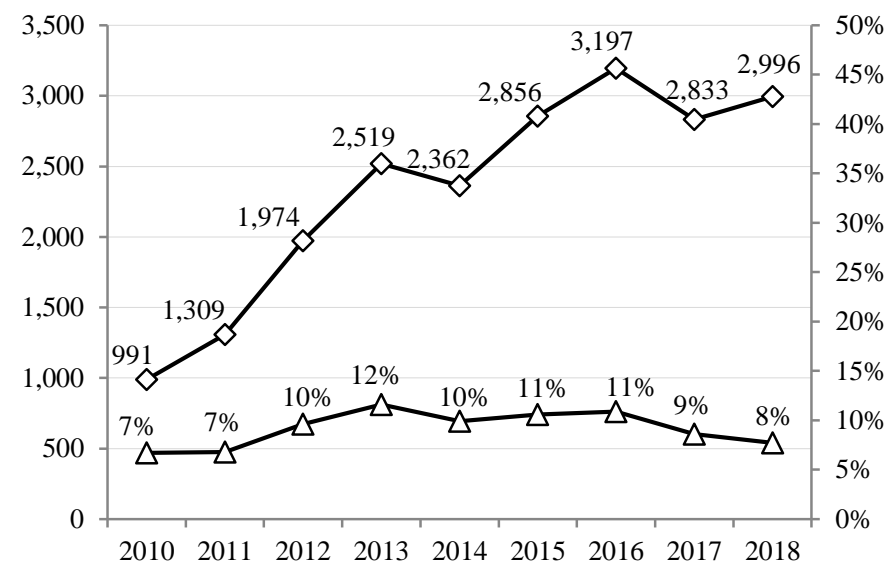

$\neg$ The volume of shipment of innovative goods, works, services in the manufacturing sector, billion rubles.

$\checkmark-$ The share of innovative goods, works, services in the total volume of shipment of the manufacturing sector, $\%$

Fig. 4. The shipment of innovative goods, works, and services in the Russian manufacturing sector [5]

It should be pointed out that a strategically significant result and indicator of innovative activity of industrial enterprises is the share of innovative goods, works, and services in the total volume of their shipment. The analysis of the dynamics of this indicator in the manufacturing sector shows that the share of innovative products has been increasing in absolute values, and has been decreasing in relative values (fig. 4). Thus, over the past 5 years, the value of sales of innovative products has increased from 2519 billion rubles to 2996 billion rubles $(+16 \%)$, but its share in the total sales of the manufacturing sector has decreased from $12 \%$ to $8 \%$ ( -4 p.p.). This situation not only indicates the absence of 
outstripping growth of innovative segments in the Russian manufacturing industries, but can also be considered as one of the signs of a crisis in the current model of innovative development of the domestic industry.

4) relatively low own investments of manufacturing enterprises in research and development, the volume of which does not allow one to form a full-fledged financial and economic basis for large-scale generation, creation and implementation of innovations in the industry. Currently, the annual amount of internal costs of processing organizations for $R \& D$ is only $90-100$ billion rubles, or $0.3 \%$ of the cost of production and sale of products (fig. 5).

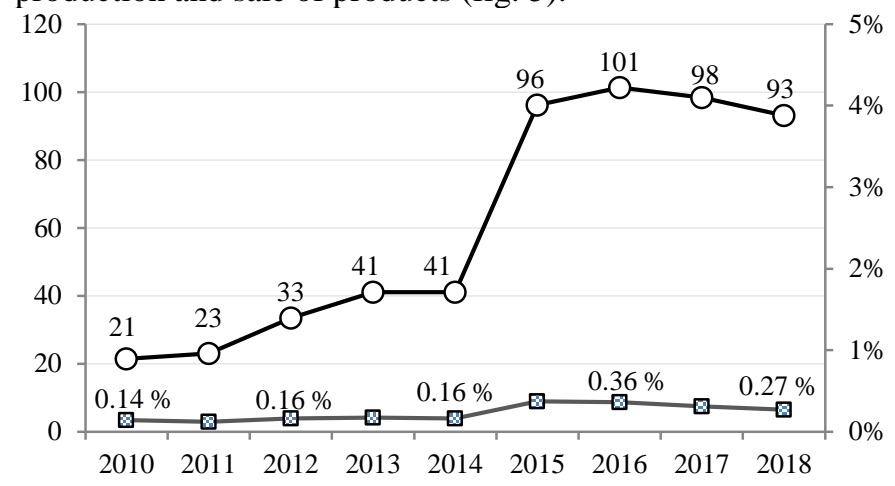

- - - Internal research and development (R\&D) expendituresin the manufacturing sector, billion rubles.

- The share of domestic expenditure on research and development costs in the manufacturing sector for the production and sale of products, $\%$

Fig. 5. Internal expenditures on research and development in the Russian manufacturing sector [5]

\section{DISCUSSION AND RESULTS}

According to the estimates of a number of experts, researchers and scientists, the problem of low dynamics of the introduction and use of innovations has existed in Russia for a long time and is caused not only by managerial and economic, but also by social factors. In 2016, during a discussion at the XX International economic forum in St. Petersburg, a recognized American scientist and Professor at the Massachusetts Institute of technology, L. R. Graham, made a historical observation that a significant part of the inventions that are currently of global importance and introduced into wide economic circulation by European and American experts were originally created in Russia, but were not patented and did not find industrial use and application in the day. According to Graham's ideas, "it's not about the technology, but the environment in which this technology is used. Russia is a clear example of the general principle that once implemented technology is not applied automatically, it does not become an integral part of the overall technological development. To support this development, we need a society that can provide this support and stimulate it - a society in which innovation becomes a natural process" [7]. According to Graham, the key to this innovative development is not the material and physical infrastructure (business incubators, technoparks, etc.) and inventions as such, but a special socioeconomic, cognitive and creative environment that provides protection and commercialization of intellectual property, contributing to the transit of ideas between business sectors, and encouraging effective competition and contestability in market institutions.

The authors share the idea that the relatively low innovative activity of Russian industry is caused not so much by infrastructure as by institutional and environmental problems and contradictions. This is confirmed by the fact that significant budget investments in recent years aimed at creating industrial clusters, technoparks, business incubators, special economic zones and other innovative structures in the domestic economy have not yet led to significant results and innovative transformations in production.

At present, innovative ecosystems can become an effective tool for creating and developing innovative environments in the Russian manufacturing sector. In their content, they represent a special barrier-free business environment and a system of relations formed by a combination of cultural, institutional and infrastructural elements, characterized by an atmosphere of high professional trust between participants, the network nature of their communications, flexible and hightech methods of work, productive business interaction, experimentation and innovation that contribute to the development and implementation of innovations.

The effectiveness of ecosystems is noted by many international researchers and practitioners [4, 8-12]. In particular, an employee of the innovation Center at the Lund Institute of Technology, C. Edqvist (Sweden), in his works, argues that "in modern conditions, innovations are born collectively, in a certain network environment based on horizontal (non-hierarchical) connections of legally independent participants" [13].

It should be mentioned that the creation and development of innovative ecosystems, especially on a regional or federal scale, is extremely difficult to ensure through state administrative and allocative procedures on a top-down basis. This is due to the fact that the ecosystem is not a material and infrastructural object, but an environment (or institution) that has developed in the process of evolution of economic relations of economic entities into partner innovative interaction.

Recognizing the crucial role of the ecosystem approach in solving the problems of innovative development of the manufacturing sector, the authors consider it appropriate to suggest the following directions for its practical implementation.

1. A consistent implementation of far-reaching reforms and institutional transformations in the manufacturing sector aimed at solving systemic problems, updating the strategic vision, improving the quality of management and speed of decision-making, adjusting the content of functions, reengineering and digitalization of business processes, optimizing organizational and structural models, and improving the skills of industrial enterprises. In the face of exponential growth of the digital economy, which changes the nature of economic relations, this work requires special dynamics and modern scientific, theoretical and 
methodological support for strategic, innovative and investment management in industry.

2. Creation of innovative pilot areas in Russia which are zones of special legal regime that provide convenient, barrierfree and extremely simple conditions for conducting innovative experiments, producing innovative products, testing knowledge-intensive technologies and implementing high-tech projects. In the scientific slang these zones have been called "regulatory innovation sandboxes". This practice has already spread abroad (Singapore, Australia, the United Kingdom, the United Arab Emirates) and is planned to be implemented in Russia as part of the national program "Digital economy of the Russian Federation". Innovative projects based on big data processing technologies, neural networks, artificial intelligence, machine learning, robotics, blockchain and other tools can become priority areas of activity for residents of regulatory sandboxes.

3. Implementation of the state industrial policy aimed at further clustering of the economy, restoration of economic ties between industrial enterprises and integration of the country's research, educational and industrial complex. The relevance of this task is due to the fact that the processing complex (like the vast majority of other sectors of the economy) is gradually moving to a new network structure based on dynamic horizontal interactions, and its enterprises, together with universities and research institutes, are integrated into flexible inter-industry structures that provide a single institutional and infrastructure environment for innovative and competitive production $[8,14]$.

4. Ensuring the priority of providing tax incentives, state subsidies and other resource support to those industrial enterprises that implement programs and projects focused on innovative transformation and digitalization of business, technological re-equipment and modernization, as well as contribute to the achievement of national goals in the development of critical technologies for the Russian Federation.

5. Further improvement of the quality of the innovation and investment climate and market mechanisms encouraging manufacturing enterprises and high-tech businesses to introduce large-scale innovations, pilot production, and make long-term investments in application-oriented research and development.

6. Improving the effectiveness of Russia's national projects directed at developing high-tech industries, stimulating business innovation and digitalizing the economy. According to preliminary data from the Ministry of Finance of the Russian Federation, the development of federal budget expenditures for the national projects "Digital economy" and "Productivity and support for employment", envisaged for 2019 , has proved to be one of the lowest and amounted to $73.8 \%$ (73.3 billion rubles) and $87.1 \%$ (6.2 billion rubles) of planned assignments, respectively.

7. Providing the Russian manufacturing sector with the necessary professional and highly qualified personnel who are able to take the process of developing and implementing of innovations to a new level, accelerate the pace of technological modernization and re-equipment of enterprises.

In practical terms, these staff, who have modern thinking and technological competence, can become the main cultural bearer and competent performer of reforms in the industry and form the country's innovation ecosystem in many ways.

Thus, increasing the innovative activity of the processing complex should be carried out on the basis of co-directional, complementary and mutually reinforcing transformations of the internal environment of the enterprises themselves and institutional transformations of the external competitive field in which they operate and develop (fig. 6).

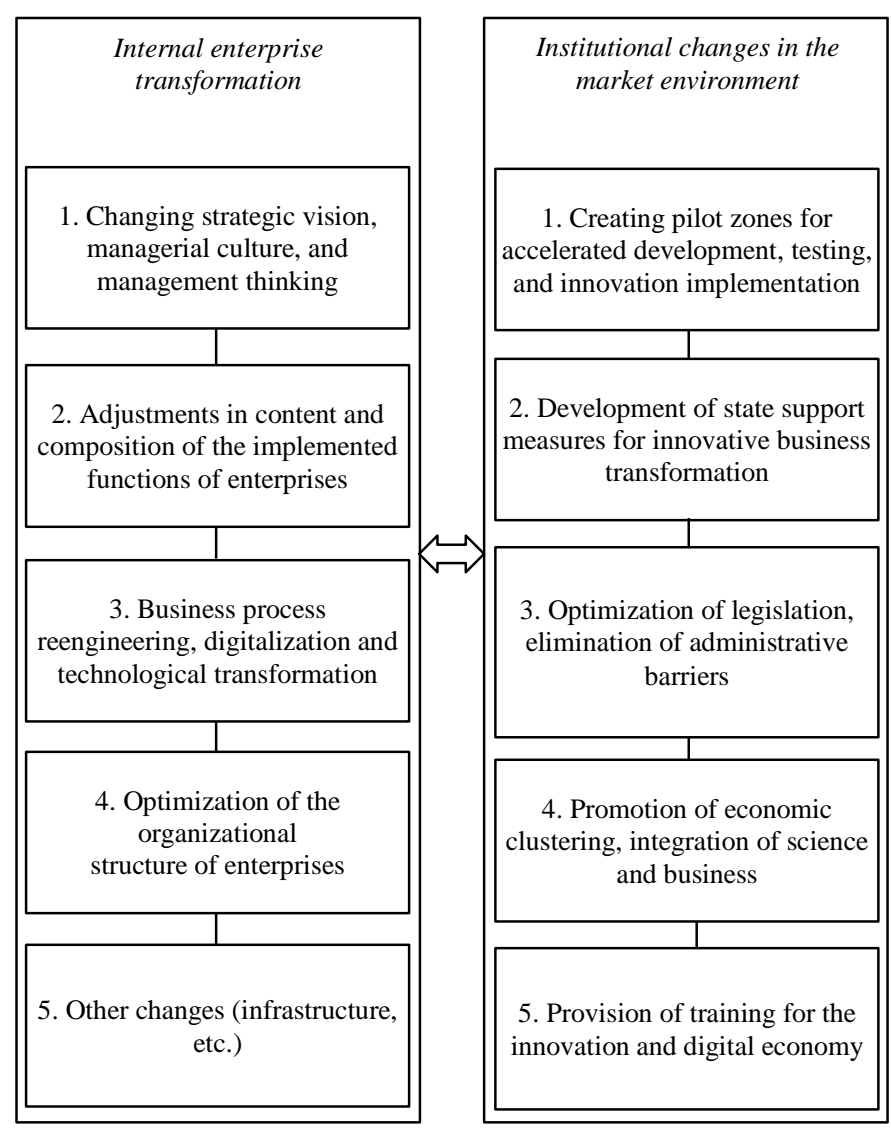

Fig. 6. The strategies of transformation and innovative development of the Russian processing complex

\section{CONCLUSION}

Currently, the Russian manufacturing sector is developing on the basis of an inefficient business model characterized by high sensitivity to external negative factors, low innovation activity of enterprises, the use of outdated management mechanisms and the use of a production base with a high level of moral and physical deterioration. This situation hinders the scientific and technological development of the country and creates increased risks to ensure its socio-economic stability.

Profound institutional, managerial, structural and other changes must be carried out in the manufacturing sector in order to transfer domestic industry to an innovative path of 
development, increase the dynamics of qualitative and quantitative production growth, and ensure the long-term competitiveness of national industrial enterprises.

In its content, these transformations should represent reforms aimed at updating the strategic course, the culture of innovative administration and management technologies, as well as the process-functional and structural algorithms of the processing complex and the industry as a whole $[15,16]$.

The most important and most difficult aspect of the transformation and innovative development of the manufacturing industry is not its technical modernization, but the creation of an innovative ecosystem in which the functioning of enterprises and scientific organizations reaches a new level of cooperation, and the systematic introduction of innovative and high-tech tools in business processes becomes the priority of the development of companies and their competition.

\section{References}

[1] Y.P. Anisimov, Y.V. Zhuravlev, I.V. Kuksova, E.I. Balabanova, A.Y. Zhilnikov, T.V. Elagina, "Spatial analysis of the development of innovative potential of enterprises", Proc. of the Voronezh State Univer. of Engineer. Technol., vol. 81, no. 1, pp. 391-396, 2019, Retrieved from: https://doi.org/10.20914/2310-1202-2019-1-391-396

[2] Y.V. Zhuravlev, I.V. Kuksova, E.A. Gubertov, L.I. Churikov, "Evaluation of innovative development of the Russian Federation based on the 2020 vision and strategy indicators", Proc. of Voronezh State Univer. of Engineer. Technol., vol. 81, no. 2, pp. 377-382, 2019, Retrieved from: https://doi.org/10.20914/2310-1202-2019-2-377-382

[3] S.V. Valdaytsev, Business valuation and innovation. Moscow: Inform. and publ. house "Filin", 2007, 352 p

[4] G.B. Kleiner "Socio-economic ecosystems in the context of dual spacetime analysis", Econ. and manag.: probl. and solutions, vol. 5-5', pp. 5-13, 2018.

[5] The Federal State Statistics Service. Retrieved from: http://www.gks.ru/ (accessed: 17.01.2020).
[6] OECD Compendium of Productivity Indicators 2019 statistics. Retrieved from: https://read.oecd-ilibrary.org/industry-andservices/oecd-compendium-of-productivity-indicators-2019_b2774f97en\#page1 (accessed: 20.01.2020). DOI https://doi.org/10.1787/b2774f97-en

[7] L. Graham, Can Russia compete? The history of innovation in imperial, Soviet, and modern Russia. Moscow: Mann, Ivanov and Ferber, 2014 $272 \mathrm{p}$.

[8] N. V. Smorodinskaya, "Network innovation ecosystems and their role in dynamizing economic growth", Innovations, vol. 7, no. 189, pp. 27-33, 2014.

[9] S.N. Larin, L.I. Gerasimova, "Institutional transformations and the formation of partnerships of scientific and industrial organizations in the development of the functional foundations of innovation", National interests: priorities and security, vol. 6, pp. 21-28, 2014.

[10] L.G. Karanatova, A.Yu. Kulev, "Modern approaches to the formation of innovative ecosystems in the emerging knowledge economy", Management consulting, vol. 12, pp. 39-46, 2015.

[11] E. Autio, L.D.W. Thomas e al., Innovation ecosystems: implications for innovation management, In The Oxford Handbook of Innovation Management. Oxford, UK: Oxford Univer. Press, 2014.

[12] R. Adner, "Ecosystem as Structure: An Actionable Construct for Strategy", J. of Manag., vol. 43, no. 1, pp. 39-58, January 2017.

[13] C. Edquist (eds.), Systems of Innovation: Perspectives and Challenges, Oxford Handbook of Innovation. Oxford: Oxford Univer. Press, November 2006, Retrieved from: https://doi.org/10.1093/oxfordhb/9780199286805.003.0007

[14] G. Parker, M. Van Alstyne, S. Choudary, Platform Revolution: How Network Markets Are Transforming the Economy - and How to Make Them Work For You. Moscow: Mann, Ivanov and Ferber, 2017.

[15] A.G. Boev, "The theoretical basis of the strategy of institutional transformations of industrial complexes in the digital economy", Models, syst., networks in econ., technol., nature and society, vol. 3, no. 31, pp. 49-61, November 2019.

[16] A.G. Boev, "Principles of institutional transformations of industrial complexes in the digital economy", Izv. of the St. Petersburg State Univer. of Econ., vol. 6, no. 120, pp. 133-139, November 2019. 